\title{
The Bioactive Compounds and Antioxidant Activity of Food Products of Rhizophora stylosa Fruit (Coffee and Tea Mangrove)
}

\author{
Dewi Indah Miranti $\mathbb{D}$, Hideaki Ichiura, and Yoshito Ohtani $\mathbb{B}$ \\ Department of Forest Science, Faculty of Agriculture, Kochi University, B-200 Monobe, Nankoku, Kochi 783-8502, Japan \\ Correspondence should be addressed to Yoshito Ohtani; ohtani@kochi-u.ac.jp
}

Received 2 September 2017; Revised 2 December 2017; Accepted 10 December 2017; Published 10 January 2018

Academic Editor: Kurt Johnsen

Copyright (C) 2018 Dewi Indah Miranti et al. This is an open access article distributed under the Creative Commons Attribution License, which permits unrestricted use, distribution, and reproduction in any medium, provided the original work is properly cited.

\begin{abstract}
The objective of this study is to investigate the bioactive compounds and antioxidant activity of coffee and tea mangrove (locally known in Indonesia) produced from the fruit of Rhizophora stylosa. Furthermore, three raw materials of coffee mangrove were also investigated to clarify their potencies. The crude extracts of five samples were subjected to antioxidant assay using DPPH. The results show that the extract of tea mangrove has the strongest activity; then, it was successfully fractionated using different polarity of solvents and yielded acetone and methanol fractions that had high antioxidant activity. The acetone fraction was purified and gave fractions $\mathrm{A} 1, \mathrm{~A} 2, \mathrm{~A} 3, \mathrm{~A} 4, \mathrm{~A} 5$, and A6, but only $\mathrm{A} 2$ and $\mathrm{A} 3$ indicated antioxidant activity and, therefore, they were subjected to further purification. Fractions A3 (caffeine) and A2 gave AS1 (N,N-dimethyl-L-alanine), AS2 (quercetin-3-O-galactopyranoside), AS3 (dodecanoic acid), and AS4 that had the similar ${ }^{1} \mathrm{H}-\mathrm{NMR}$ spectrometric results with AS2, while the methanol fraction did not exhibit clear peaks on the chromatogram by HPLC. Therefore, the precipitation method was conducted to purify this fraction, and the precipitate was analyzed by NMR spectra. The results from ${ }^{1} \mathrm{H}$ and ${ }^{13} \mathrm{C}$ NMR indicate that this fraction is a typical polymer of condensed tannins, containing procyanidin and prodelphinidin units.
\end{abstract}

\section{Introduction}

Mangroves are defined as the type of forest comprising woody plants or shrubs, living at the interface of land and sea in tropical and subtropical coastline [1-3]. The uses of mangroves can be classified at two major categories. Firstly, mangroves as buffer area to protect the coast from erosion, stabilize the sedimentation, and purify the coastal polluted water. Secondly, mangroves provide various products such as timber, fuel, food, and medicine and also are a source of bioactive compounds $[1,2]$.

Bioactive compounds are used not only for medicinal purpose, but also for functional food consumption [4]. Those bioactive compounds have beneficial effects for human health, for example, a role of antioxidant. Antioxidants possess an ability to scavenge free radicals, which cause many degenerative diseases. Some food resources of mangroves, such as the hypocotyl of Kandelia candel and the edible part of ripe and unripe Nypa fruticans fruit, have antioxidant activity due to the presence of phenolics [5-7]. It was reported by Bunyapraphatsara et al. [8] that the edible part of Rhizophora mucronata (young pods) exhibited the strong antioxidant activity. Several reports mentioned above indicate that further exploration of food originating from mangrove is important in order to find a new variety of the functional food materials.

Rhizophora stylosa is one of the dominant species in mangrove area of Indonesia, especially in Pamekasan Regency East Java. The fruit part including cotyledon is processed to coffee and tea within local society in this area. Coffee and tea mangrove have been manufactured by household industry since 2012 and 2015, respectively. Local folks who daily take both products recognize physiological activities, such as rejuvenation and fitness improvement. It means that some bioactive compounds in these products may exhibit such effects; however, no scientific evidence has been elucidated. 


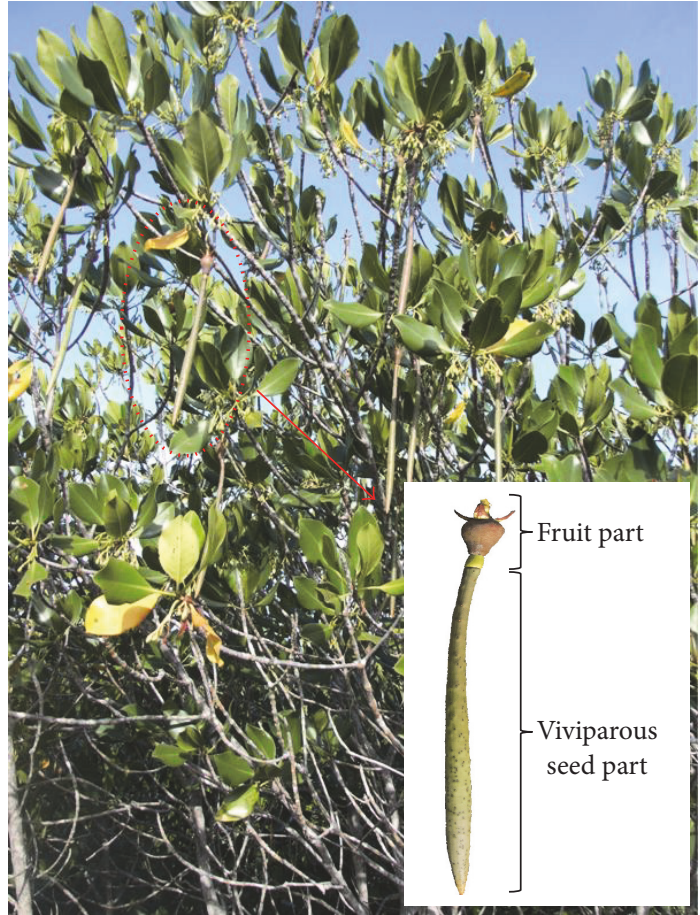

Figure 1: Photographs of Rhizophora stylosa and its seed.

Further study is desirable to clarify their phenomena; therefore, investigation of bioactive compounds and antioxidant activity of coffee and tea mangrove has been conducted in this research.

\section{Materials and Methods}

2.1. Chemicals. BHA, BHT, trolox, and 1,1-diphenyl-2-picrylhydrazyl (DPPH) were from Nacalai Tesque, Inc. (Japan). All solvents (methanol, acetone, n-hexane, and ethyl acetate) used in this study were from Wako Pure Chemical Industries, Ltd. (Osaka, Japan).

2.2. Coffee and Tea Mangrove Materials. Coffee and tea mangrove were brought from Pamekasan Regency, East Java, Indonesia, in 2016. Both products are made from the fruit (including cotyledon) of species $R$. stylosa (Figure 1). This species bears viviparous seed. Their germination and seedling development actually occur on parent plant [9]. When seedling is matured and ready for regeneration, the fruit part (including cotyledon) is left useless on the tree. The fruit part is, therefore, used as the main ingredient of coffee and tea mangrove.

The coffee mangrove is composed of the powders of mangrove fruits, gingers (Zingiber officinale), and Javanese long peppers (Piper retrofractum); all ingredients are prepared through sun-drying, roasting, and grinding processes. The supplemental materials such as ginger and Javanese long pepper are added as the flavor to enhance the coffee taste. Meanwhile, tea mangrove is a plain coarse powder from mangrove fruits without roasting process and supplemental materials.
In this study, the powder of mangrove fruit (R. stylosa), coffee mangrove, tea mangrove, ginger, and Javanese long pepper were used to clarify their potencies.

2.3. Extraction. Each powder of coffee mangrove, tea mangrove, mangrove fruit, ginger, and Javanese long pepper was extracted two times using $100 \%$ methanol (5 times volumes) at room temperature for 3 days each time. The methanol filtrates were evaporated using a rotary evaporator under reduced pressure at $45^{\circ} \mathrm{C}$ and then vacuum-dried to yield the crude extracts.

2.4. Isolation Procedures. The highest antioxidant activity was found in tea mangrove extract. $10 \mathrm{~g}$ of crude extract of tea mangrove was subjected to open column chromatography over silica-gel and eluted with solvents of increasing polarity from n-hexane (100\%), n-hexane and ethyl acetate (50\% : 50\%), acetone (100\%), and methanol (100\%) to yield nhexane (10 mg), n-hexane and ethyl acetate (900 mg), acetone (510 mg), and methanol (4240 mg) fractions, respectively (Table 2). All fractions were subjected to the antioxidant assay using DPPH, as a result acetone and methanol fractions exhibited high activity compared to the others.

Acetone fraction ( $510 \mathrm{mg}$ ) was further fractionated by HPLC (pump: L7110, detector (UV $254 \mathrm{~nm}$ ): L7420, Hitachi Co.) at room temperature. First purification by HPLC was performed using ODS column (Mightysil, RP-18 GP 25020, Kanto Chemicals Co.), eluted with $100 \%$ of methanol at flow rate $3 \mathrm{~mL} / \mathrm{min}$, and gave 6 fractions: $\mathrm{A} 1$ (13.7 $\mathrm{mg})$, A2 (420.6 mg), A3 (12.7 mg), A4 (10.7 mg), A5 (5.3 mg), and A6 $(22.7 \mathrm{mg})$. Among them, A2 exhibited high antioxidant activity and $\mathrm{A} 3$ also had relatively high antioxidant activity; therefore, second fractionation of A2 and purification of A3 by HPLC were performed by silica-gel semipreparative column (Wakosil 5SIL, Wako Chemicals Co.), eluted with n-hexane and ethyl acetate (50\%:50\%), and A2 gave four compounds based on peaks: AS1 (2.5 mg), AS2 (2.9 mg), AS3 (3.5 mg), and AS4 (5.2 mg), and A3 gave single compound (2 mg).

For methanol fraction, a $605 \mathrm{mg}$ of sample was dissolved in $10 \mathrm{~mL}$ methanol and added to $10 \mathrm{~mL}$ of benzene, to obtain precipitate (the process was done twice). The precipitate was filtered using a filter paper and vacuum-dried. Then, the purified acetone fraction A3 and the four subfractions, AS1, AS2, AS3, and AS4 and the $30 \mathrm{mg}$ of dried precipitate from methanol fraction were subjected to further analyses using LC-MS and NMR.

The $50 \mathrm{mg}$ of dried precipitate from methanol fraction was dissolved in $\mathrm{KOH}$-methanol and methylated with dimethyl sulfate at room temperature. Then distilled water was added to this solution and the methylated compound was extracted with ethyl acetate. The resulting methylated compound from methanol fraction was analyzed by HPLC using GPC column (TSK gel G2000HS, Toso Co.) with chloroform.

2.5. LC-MS and NMR Analyses. Mass spectra were recorded using LCMS-8040 (Shimadzu, Japan), column, ODS $5 \mu \mathrm{m}$, $\varnothing 4.6 \mathrm{~mm} \times 150 \mathrm{~mm}$ (GL Science Co.); solvent was mixture 
of methanol and water (gradient; starting (50\%:50\%) to $100 \%$ methanol). NMR spectra were recorded at $500 \mathrm{MHz}$ for ${ }^{1} \mathrm{H}$ and $125 \mathrm{MHz}{ }^{13} \mathrm{C}$ on JNM-ECX500 system (JEOL Ltd.). Samples were dissolved in methanol $d$-4. The chemical shifts were expressed in $\mathrm{ppm}(\delta)$ and were as follows: A3 (caffeine): LC-MS positive ion $(\mathrm{m} / z) 195[\mathrm{MH}]^{+} ;{ }^{1} \mathrm{H}-\mathrm{NMR}$ (methanol $d-4,500 \mathrm{MHz}, \mathrm{ppm}): \delta 3.3(3 \mathrm{H}, \mathrm{s}, \mathrm{H}-1), 3.5(3 \mathrm{H}, \mathrm{s}$, $\mathrm{H}-3), 4.0$ (3H, s, H-5), 7.9 (1H, s, H-6); ${ }^{13} \mathrm{C}-\mathrm{NMR}$ (methanol $d-4,125 \mathrm{MHz}, \mathrm{ppm}): \delta 28.2$ (C-3), 30.1 (C-1), 33.9 (C-6), 108.7 (C-5), 143.9 (C-7), 149.8 (C-8), 153.2 (C-2), 156.7 (C-4). AS1 (N,N-dimethyl-L-alanine): LC-MS positive ion $(\mathrm{m} / z) 117$ $M^{+} ;{ }^{1} \mathrm{H}-\mathrm{NMR}$ (methanol d-4, $\left.500 \mathrm{MHz}, \mathrm{ppm}\right): \delta 1.2(3 \mathrm{H}, \mathrm{s}$, $\left.\mathrm{CH}_{3}\right), 2.5\left(6 \mathrm{H}, \mathrm{s}, 2 \mathrm{CH}_{3}\right) ;{ }^{13} \mathrm{C}-\mathrm{NMR}$ (methanol d-4, $125 \mathrm{MHz}$, ppm): $\delta 27.6\left(\mathrm{CH}_{3}\right), 28.0\left(\mathrm{CH}_{3}\right), 30.2(\mathrm{CH}), 174.3(\mathrm{COOH})$. AS2 (quercetin-3-O-galactopyranoside): LC-MS positive ion $(\mathrm{m} / z) 445[\mathrm{M}-\mathrm{H}]^{+} ;{ }^{1} \mathrm{H}-\mathrm{NMR}$ (methanol d-4, $\left.500 \mathrm{MHz}, \mathrm{ppm}\right)$ : $\delta 5.38 \mathrm{~d}, J=7.5 \mathrm{~Hz}, \mathrm{H}-1^{\prime \prime}, 6.27 \mathrm{~d}, J=2.0 \mathrm{~Hz}, 1 \mathrm{H}, \mathrm{H}-6$, $6.78 \mathrm{~d}, J=2.0 \mathrm{~Hz}, 1 \mathrm{H}, \mathrm{H}-8,6.93 \mathrm{~d}, J=8.5 \mathrm{~Hz}, \mathrm{H}-5^{\prime}, 7.49 \mathrm{~d}$, $J=2.2 \mathrm{~Hz}, \mathrm{H}-2^{\prime}, 7.57 \mathrm{dd}, \mathrm{J} 1=2.2 \mathrm{~Hz}, \mathrm{~J} 2=8.5 \mathrm{~Hz}, \mathrm{H}-6^{\prime}$, 3.74-3.26 m, 6H; ${ }^{13} \mathrm{C}-\mathrm{NMR}$ (methanol d- $4,125 \mathrm{MHz}, \mathrm{ppm}$ ): $\delta 61.0\left(\mathrm{C}-6^{\prime \prime}\right), 68.9\left(\mathrm{C}-4^{\prime \prime}\right), 70.3\left(\mathrm{C}-2^{\prime \prime}\right), 71.9\left(\mathrm{C}-3^{\prime \prime}\right), 76.0(\mathrm{C}-$ 5"), 97.7 (C-6, C-8), $103.7\left(\mathrm{C}-1^{\prime \prime}\right), 108.0$ (C-10), $114.9\left(\mathrm{C}-2^{\prime}\right)$, $115.6\left(\mathrm{C}-5^{\prime}\right), 115.8\left(\mathrm{C}-1^{\prime}\right), 117.4\left(\mathrm{C}-6^{\prime}\right), 131.0(\mathrm{C}-3), 141.1(\mathrm{C}-$ $\left.3^{\prime}\right), 144.0$ (C-4' $), 156.5$ (C-2, C-9), 158.0 (C-5), 168.5 (C-7), 174.0 (C-4). AS3 (dodecanoic acid): LC-MS positive ion $(\mathrm{m} / \mathrm{z}$ ) $200 \mathrm{M}^{+} ;{ }^{1} \mathrm{H}-\mathrm{NMR}$ (methanol d-4, $\left.500 \mathrm{MHz}, \mathrm{ppm}\right): \delta 0.8(3 \mathrm{H}$, $\left.\mathrm{m}, \mathrm{CH}_{3}\right), 1.2\left(20 \mathrm{H}, \mathrm{m}, 10 \mathrm{CH}_{2}\right) ;{ }^{13} \mathrm{C}-\mathrm{NMR}$ (methanol d- 4,125 $\mathrm{MHz}, \mathrm{ppm}): \delta 13.1\left(\mathrm{CH}_{3}\right), 22.4\left(\mathrm{CH}_{2}\right), 29.2\left(\mathrm{CH}_{2}\right), 31.8\left(\mathrm{CH}_{2}\right)$, $175.0(\mathrm{COOH})$.

2.6. DPPH Assay. The assay for DPPH radical scavenging activity was performed to find out the antioxidant activity of the extracts and their fractions on preliminary and evaluation stages. Sample was added to a mixture $(1.8 \mathrm{~mL})$ of $0.25 \mathrm{mM}$ DPPH in methanol solution, methanol, and acetic buffer solution to make final concentrations $0,1.10,2.19,3.27$, $4.34,5.40,10.52,13.47$, and $43.48 \mu \mathrm{g} / \mathrm{mL}$. Absorbance was measured at $520 \mathrm{~nm}$ by spectrophotometer U-2810 (Hitachi Ltd.). BHA, BHT, and trolox were used as positive controls. The DPPH radical scavenging activity was calculated by the following equation:

DPPH radical scavenging activity (\%)

$$
=\frac{100\left(A_{0}-A c\right)}{A_{0}}
$$

wherein $A c$ was the absorbance of the solution with sample and $A_{0}$ was the absorbance of the solution without sample. The $\mathrm{IC}_{50}$, half maximal inhibitory concentration, was calculated using regression analysis and used to represent the activity of the substrate [10]. The assays were carried out in triplicate.

2.7. Statistical Analysis. The data were expressed as mean \pm standard deviation (SD) in triplicate assays of antioxidant activity. One-way analysis of variance (ANOVA) was performed with SPSS 16 followed by Duncan's test to determine the significant differences between values at $p<0.05$.
TABLE 1: Methanol extractive yields of the samples.

\begin{tabular}{lc}
\hline Sample & Extractives yield (\%) \\
\hline Mangrove fruit powder & 4.22 \\
Coffee mangrove & 3.78 \\
Tea mangrove & 7.45 \\
Ginger powder & 7.23 \\
Javanese long pepper powder & 8.70 \\
\hline
\end{tabular}

TABLE 2: Stepwise fractionation of the extracts of tea mangrove with different solvents.

\begin{tabular}{lc}
\hline Fractions & Yield (mg) \\
\hline n-Hexane & 10 \\
n-Hexane \& ethyl acetate & 900 \\
Acetone & 510 \\
Methanol & 4240 \\
\hline
\end{tabular}

\section{Results and Discussion}

3.1. Extraction Yields of Samples. Many studies have been conducted to extract and isolate bioactive compounds from plant material for utilization in food or pharmacy. Bioactive compounds range from polar compounds to nonpolar compounds, and the selected solvent affects efficiency of extraction. The types of solvent commonly used are alcohol (methanol and ethanol), acetone, diethyl ether, and ethyl acetate $[11,12]$. In this study, the extract yields of the samples with methanol as a solvent range from 3.78\% to $8.70 \%$ (Table 1). The highest extract yield was of Javanese long pepper and the lowest was of coffee mangrove.

The tea mangrove extract was successively eluted with different solvents on silica-gel open column. The yield of each fraction was shown in Table 2. Methanol fraction (4240 mg) was dominant, and n-hexane and ethyl acetate fraction $(900 \mathrm{mg})$ and acetone fraction $(510 \mathrm{mg})$ were followed.

3.2. Isolation and Structure Identification. The acetone fraction was divided into the fractions $\mathrm{A} 1, \mathrm{~A} 2, \mathrm{~A} 3, \mathrm{~A} 4, \mathrm{~A} 5$, and A6 by HPLC with ODS column; however, only A2 and A3 indicated antioxidant activity in the preliminary test. Main fraction A2 (420.6 mg) was further subjected to HPLC with semipreparative silica-gel column and gave four compounds AS1-AS4 based on the peaks which amounted to only $14.1 \mathrm{mg}$. Most of A2 that could not be separated well seemed to be oligomer or polymer-like as methanol fraction mentioned later. A3 was rather single compound; therefore, it was purified by HPLC with silica-gel column. The compounds AS1-AS4 and A3 were analyzed by LC-MS and NMR spectra.

LC-MS analysis of A3 showed the molecular weight of $m / z$ 195. Based on the ${ }^{1} \mathrm{H}$ - and ${ }^{13} \mathrm{C}$-NMR spectral data and compared with previous studies $[13,14]$, A3 was identified as caffeine.

AS1, AS2, and AS3 were identified as N,N-dimethylL-alanine, quercetin-3-O-galactopyranoside [15], and dodecanoic acid, respectively (Figure 2). However, AS2 contained small quantity of impurity whose ${ }^{1} \mathrm{H}$-NMR spectrum had 
<smiles>Cn1c(=O)c2c(ncn2C)n(C)c1=O</smiles>

(a)<smiles>CC(C(=O)O)N(C)C</smiles>

(b)

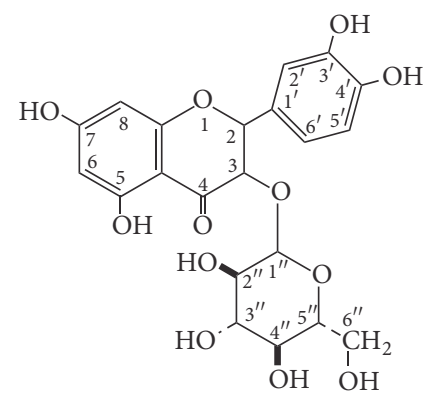

(c)

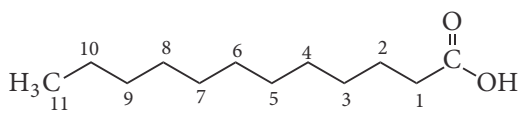

(d)

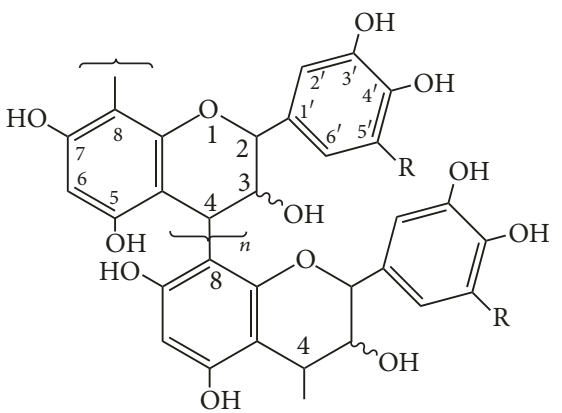

(A) $\mathrm{R}=\mathrm{H}$, procyanidin $(\mathrm{PC})$

(B) $\mathrm{R}=\mathrm{OH}$, prodelphinidin $(\mathrm{PD})$

(e)

FIGURE 2: Chemical structures of caffeine (a), N,N-dimethyl-L-alanine (b), quercetin-3-O-galactopyranoside (c), dodecanoic acid (d), and condensed tannins (e).

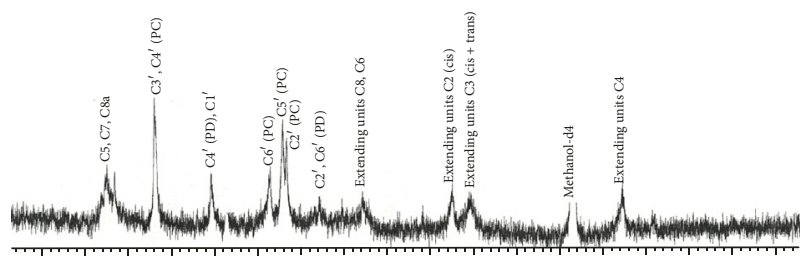

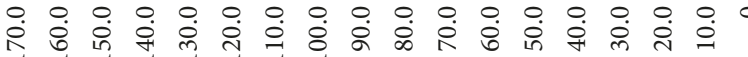

FIGURE 3: ${ }^{13} \mathrm{C}$-NMR spectrum of the purified methanol fraction from tea mangrove extract.

the signals assigned to theanine [16]. ${ }^{1} \mathrm{H}-\mathrm{NMR}$ spectrum of AS4 was similar to that of AS2, but the signals at $3.2-4.4 \mathrm{ppm}$ were stronger and more complicated. It means AS4 may be like quercetin-3-O-(2" $-\mathrm{O}$-glucopyranoside)galactopyranoside [17]. A2 showed mostly broad peaks on HPLC and seemed not to be a single compound.

Methanol fraction of tea mangrove extract did not give any single compounds by HPLC; therefore, it was purified by precipitation method. Then, the precipitate was analyzed by NMR spectra. As shown in Figure $3,{ }^{13} \mathrm{C}-\mathrm{NMR}$ spectrum of the precipitate reveals a typical polymer of condensed tannins, containing procyanidin (dominant) and prodelphinidin (minor) units $[18,19]$. The signal assignment was compared based on previous study [18-21]. The peaks at 150 and 160 ppm (C5, C7, C8a), 143.8 ppm (C3' $\left.{ }^{\prime} 4^{\prime}\right), 114.2$ to 118 ppm
$\left(\mathrm{C} 2^{\prime}, \mathrm{C}^{\prime}\right.$ and $\mathrm{C}^{\prime}$ ), and 94 to $100 \mathrm{ppm}$ (C8 and C6) showed the presence of procyanidin units (PC). Then, the peaks at $131 \mathrm{ppm}\left(\mathrm{C}^{\prime}, \mathrm{C1}^{\prime}\right)$ and 104 to $108 \mathrm{ppm}\left(\mathrm{C}^{\prime}, \mathrm{C}^{\prime}\right)$ showed the presence of prodelphinidin units (PD). In addition, the ratio of 2,3-cis to 2,3-trans isomers could be determined through the distinct differences in their respective $\mathrm{C} 2$ chemical shifts from the region peaks area between 70 and 90 ppm [18, 21]. The $\mathrm{C} 2$ gave resonance at $75 \mathrm{ppm}$ for cis form, but the resonance for trans form was not detected. It indicates that terminal units were all in cis form [21]. The C3 signals of both cis and trans isomers occurred at $71 \mathrm{ppm}$ and at $36 \mathrm{ppm}$ showed the extension units of $\mathrm{C} 4$ atoms.

GPC chromatogram of methylated methanol fraction purified by precipitation is shown in Figure 4. A few peaks appear at 1830, 1400, and 780 of molecular weights which correspond to pentamer, tetramer, and dimer, respectively. As a consequence, the average DP (degree of polymerization) is estimated to be around 4 and 5 . It has been reported that procyanidin isolated from Camellia sinensis had 5.44 of average DP [22]. DP of the condensed tannins isolated from tea mangrove seems to be slightly lower than $C$. sinensis.

3.3. Antioxidant Activity. The assay of antioxidant activity was conducted within the extracts, fractionated materials, and some isolated compounds. Firstly, the assay was preliminarily to clarify the potency of each sample. Among those samples, tea mangrove exhibited the highest antioxidant activity with $\mathrm{IC}_{50}$ less than $\mathrm{BHA}\left(\mathrm{IC}_{50} 1.56 \mu \mathrm{g} / \mathrm{mL}\right)$ but higher than trolox $\left(\mathrm{IC}_{50} 4.21 \mu \mathrm{g} / \mathrm{mL}\right)$. The other two extracts from 


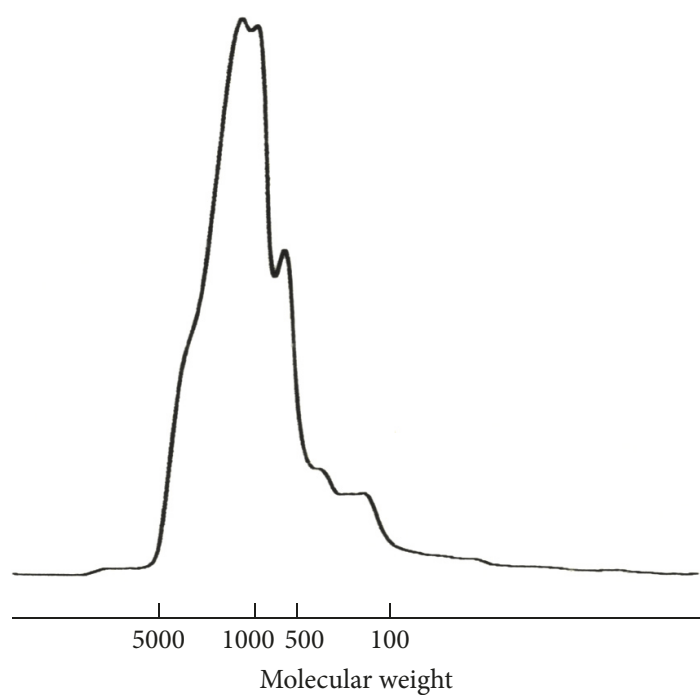

FIGURE 4: GPC chromatogram of the methylated methanol fraction of tea mangrove extract.

TABLE 3: Antioxidant activity of samples.

\begin{tabular}{lc}
\hline Sample & $\mathrm{IC}_{50}(\mu \mathrm{g} / \mathrm{mL})$ \\
\hline Mangrove fruit powder & $4.51^{\mathrm{bc}} \pm 0.12$ \\
Coffee mangrove & $5.25^{\mathrm{c}} \pm 0.12$ \\
Tea mangrove & $4.13^{\mathrm{b}} \pm 0.05$ \\
Ginger powder & $13.57^{\mathrm{d}} \pm 0.35$ \\
Javanese long pepper powder & $61.84^{\mathrm{e}} \pm 1.31$ \\
Trolox & $4.21^{\mathrm{b}} \pm 0.31$ \\
BHA & $1.56^{\mathrm{a}} \pm 0.20$ \\
BHT & $4.52^{\mathrm{bc}} \pm 0.49$ \\
\hline
\end{tabular}

The data were expressed as mean \pm standard deviation. The different values in the same column indicate significant differences $(p<0.05)$.

mangrove fruit powder and coffee mangrove have partially good potent activity mostly equal to $\mathrm{IC}_{50}$ of trolox and BHT ( $\mathrm{IC}_{50} 4.52 \mu \mathrm{g} / \mathrm{mL}$ ) as the positive controls (Table 3), while two samples, ginger and Javanese long pepper, have relatively low activity. High antioxidant activities of coffee and tea mangroves are therefore originated from mangrove fruit.

Tea mangrove extract had the strongest radical scavenging activity; therefore it was fractionated successively using 4 different solvents (Table 2). Among them, acetone and methanol fractions had high antioxidant activity (Table 4). Both fractions were subjected to HPLC in order to isolate some compounds from these fractions.

The compound A3 (caffeine) and the purified methanol fraction (condensed tannins) obtained from tea mangrove extract were subjected to the antioxidant assay; the results are shown in Table 5. Caffeine exhibits low antioxidant activity $\left(I_{50} 83.69 \mu \mathrm{g} / \mathrm{mL}\right.$ ), but condensed tannin (procyanidin), which mainly constitutes the acetone and methanol fractions of tea mangrove extract, has high antioxidant activity $\left(I C_{50}\right.$ $2.69 \mu \mathrm{g} / \mathrm{mL}$ ). The compounds AS2 and AS4, both quercetin derivatives, may have antioxidant activity considerably [23],
TABLE 4: Antioxidant activity of the fractions from tea mangrove extract.

\begin{tabular}{lc}
\hline Sample & $\mathrm{IC}_{50}(\mu \mathrm{g} / \mathrm{mL})$ \\
\hline n-Hexane & $58.26^{\mathrm{c}} \pm 4.26$ \\
n-Hexane \& ethyl acetate & $22.99^{\mathrm{b}} \pm 0.34$ \\
Acetone & $4.38^{\mathrm{a}} \pm 0.10$ \\
Methanol & $2.66^{\mathrm{a}} \pm 0.11$ \\
\hline
\end{tabular}

The data were expressed as mean \pm standard deviation. The different values in the same column indicate significant differences $(p<0.05)$.

TABLE 5: Evaluation assay for antioxidant activity of two compounds from tea mangrove extract.

\begin{tabular}{lc}
\hline Compound & IC50 $(\mu \mathrm{g} / \mathrm{mL})$ \\
\hline Purified methanol fraction (condensed tannins) & $2.69 \pm 0.04$ \\
Caffeine & $83.69 \pm 4.86$ \\
\hline
\end{tabular}

but their quantities are very little. In conclusion, antioxidant activities of tea mangrove extract or mangrove fruit extract are mostly induced by the condensed tannins.

The tannins are able to donate electrons to free radicals, stabilize them, and alleviate harmful radical structures [24]. Several studies have also demonstrated the free radical scavenging activity of the condensed tannins $[18,19,25$, 26]. Therefore, mangrove fruit which is abundant in the condensed tannins must be the potential antioxidant agent.

\section{Conflicts of Interest}

The authors have no conflicts of interest to declare regarding the publication of this paper.

\section{Acknowledgments}

This research was supported by Japanese Government (Monbukagakusho: Mext) Scholarship Program and United Graduate School of Agricultural Sciences Ehime University.

\section{References}

[1] D. M. Alongi, "Paradigm Shifts in Mangrove Biology," in Coastal Wetlands: An Integrated Ecosystem Approach, G. M. E. Perillo, E. Wolanski, D. R. Cahoon, and M. M. Brinson, Eds., pp. 632-633, Elsevier, New York, NY, USA, 2009.

[2] W. M. Bandaranayake, "Bioactivities, bioactive compounds and chemical constituents of mangrove plants," Wetlands Ecology and Management, vol. 10, no. 6, pp. 421-452, 2002.

[3] P. Hogarth, The Biology of Mangroves and Seagrasses, Oxford University Press, New York, NY, USA, 2007.

[4] C. Raghuveer and R. V. Tandon, "Review article: consumption of functional food and our health concerns," Pakistan Journal of Physiology, vol. 5, pp. 76-83, 2009.

[5] W. M. Bandaranayake, "Traditional and medicinal uses of mangroves," Mangroves and Salt Marshes, vol. 2, no. 3, pp. 133-148, 1998.

[6] N. Prasad, B. Yang, K. W. Kong et al., "Phytochemicals and antioxidant capacity from Nypa fruticans Wurmb. Fruit," 
Evidence-Based Complementary and Alternative Medicine, vol. 2013, Article ID 154606, 9 pages, 2013.

[7] S.-D. Wei, H.-C. Zhou, and Y.-M. Lin, "Antioxidant activities of extract and fractions from the hypocotyls of the mangrove plant Kandelia candel," International Journal of Molecular Sciences, vol. 11, no. 10, pp. 4080-4093, 2010.

[8] N. Bunyapraphatsara, A. Jutiviboonsuk, V. Srisukh et al., "Vegetables from the mangrove areas," Thai Journal of Phytopharmacy, vol. 9, pp. 1-12, 2002.

[9] P. B. Tomlinson, Seedlings and Seeds. The Botany of Mangroves, Cambridge University Press, UK, 2nd edition, 2016.

[10] P. Molyneux, "The use of the stable radical Diphenylpicrylhydrazyl (DPPH) for estimating antioxidant activity," Songklanakarin Journal of Science and Technology, vol. 26, no. 2, pp. 211-219, 2004.

[11] A. Dailey and Q. V. Vuong, "Effect of extraction solvents on recovery of bioactive compounds and antioxidant properties from macadamia (Macadamia tetraphylla) skin waste," Cogent Food \&amp; Agriculture, vol. 1, no. 1, Article ID 1115646, pp. 1-10, 2015.

[12] C. D. Stalikas, "Review: extraction, separation, and detection methods for phenolic acids and flavonoids," Journal of Separation Science, vol. 30, no. 18, pp. 3268-3295, 2007.

[13] J. Hayakawa and M. Kamata, Isolation of Caffeine by Using Sublimation from Tea Leaves and the Utilization for Chemical Teaching Material of Instrumental Analytical Experiment, Bulletin of The Faculty of Education. Natural Sciences. Nigata University, 2014.

[14] J. Sitkowski, L. Stefaniak, L. Nicol, M. L. Martin, G. J. Martin, and G. A. Webb, "Complete assignments of the 1H, 13C and 15N NMR spectra of caffeine," Spectrochimica Acta Part A: Molecular and Biomolecular Spectroscopy, vol. 51, no. 5, pp. 839-841, 1995.

[15] M. Sikorska, I. Matławska, K. Glowniak, and G. Zgorka, “Qualitative and quantitative analysis of phenolic acids in Asclepias syriaca L," Acta Poloniae Pharmaceutica - Drug Research, vol. 57, no. 1, pp. 69-72, 2000.

[16] G. Le Gall, I. J. Colquhoun, and M. Defernez, "Metabolite Profiling Using 1H NMR Spectroscopy for Quality Assessment of Green Tea, Camellia sinensis (L.)," Journal of Agricultural and Food Chemistry, vol. 52, no. 4, pp. 692-700, 2004.

[17] Z. P. Xiao, H. K. Wu, T. Wu, H. Shi, B. Hang, and H. A. Aisa, "Kaempferol and quercetin flavonoids from Rosa rugosa," Chemistry of Natural Compounds, vol. 42, no. 6, pp. 736-737, 2006.

[18] L.-L. Zhang, Y.-M. Lin, H.-C. Zhou, S.-D. Wei, and J.-H. Chen, "Condensed tannins from mangrove species Kandelia candel and Rhizophora mangle and their antioxidant activity," Molecules, vol. 15, no. 1, pp. 420-431, 2010.

[19] L. Z. Liang and M. L. Yi, "HPLC, NMR and MALDI-TOF MS analysis of condensed tannins from Lithocarpus glaber leaves with potent free radical scavenging activity," Molecules, vol. 13, no. 12, pp. 2986-2997, 2008.

[20] Z. Czochanska, L. Y. Foo, R. H. Newman, and L. J. Porter, "Polymeric proanthocyanidins. Stereochemistry, structural units, and molecular weight," Journal of the Chemical Society, Perkin Transactions 1, vol. 1, pp. 2278-2286, 1980.

[21] X.-X. Chen, Y. Shi, W.-M. Chai, H.-L. Feng, J.-X. Zhuang, and Q.-X. Chen, "Condensed tannins from Ficus virensas tyrosinase inhibitors: Structure, inhibitory activity and molecular mechanism," PLoS ONE, vol. 9, no. 3, Article ID e91809, 2014.
[22] X. Jiang, Y. Liu, Y. Wu et al., "Analysis of accumulation patterns and preliminary study on the condensation mechanism of proanthocyanidins in the tea plant [Camellia sinensis]," Scientific Reports, vol. 5, article no. 8742, 2015.

[23] J.-H. Moon, T. Tsushida, K. Nakahara, and J. Terao, "Identification of quercetin 3-O- $\beta$-D-glucuronide as an antioxidative metabolite in rat plasma after oral administration of quercetin," Free Radical Biology \& Medicine, vol. 30, no. 11, pp. 1274-1285, 2001.

[24] V. Koleckar, K. Kubikova, Z. Rehakova et al., "Condensed and hydrolysable tannins as antioxidants influencing the health," Mini-Reviews in Medicinal Chemistry, vol. 8, no. 5, pp. 436-447, 2008.

[25] D.-L. Li, X.-M. Li, Z.-Y. Peng, and B.-G. Wang, "Flavanol derivatives from Rhizophora stylosa and their DPPH radical scavenging activity," Molecules, vol. 12, no. 5, pp. 1163-1169, 2007.

[26] M. A. Zarin, H. Y. Wan, A. Isha, and N. Armania, "Antioxidant, antimicrobial and cytotoxic potential of condensed tannins from leucaena leucocephala hybrid-rendang," Food Science and Human Wellness, vol. 5, no. 2, pp. 65-75, 2016. 

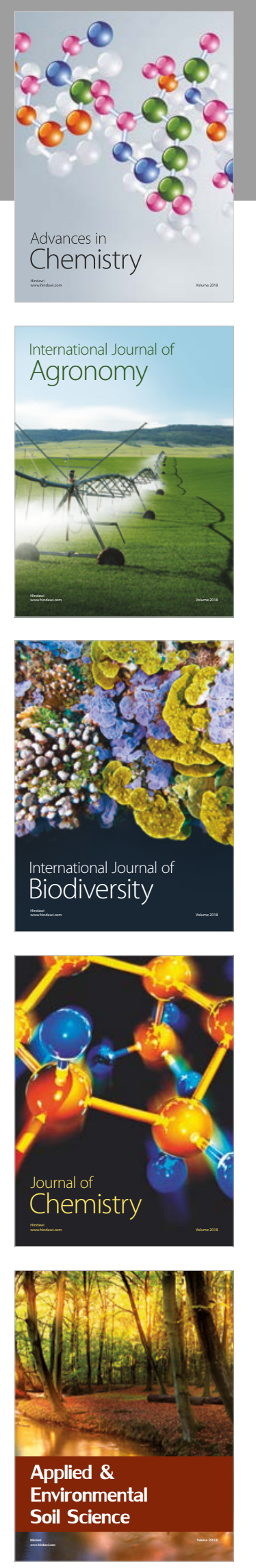

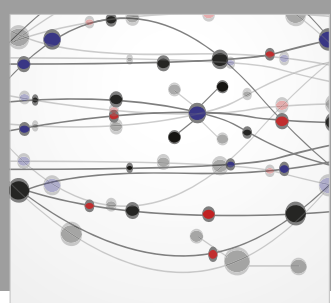

The Scientific World Journal

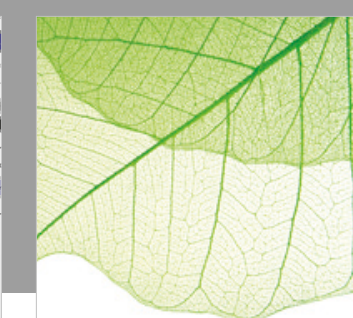

Journal of Botany

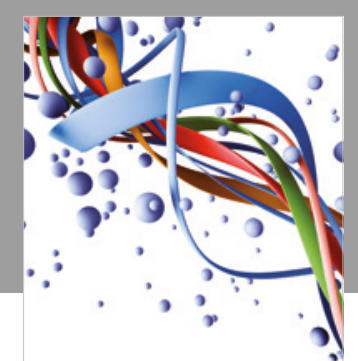

Scientifica

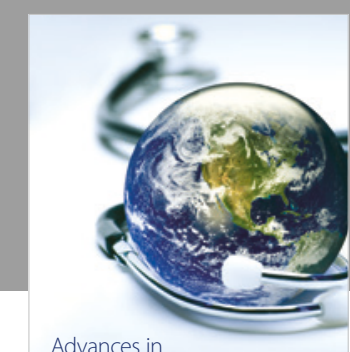

Public Health

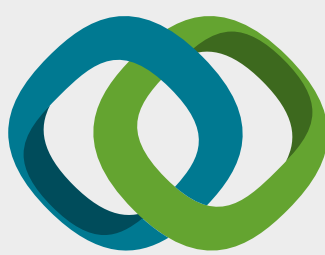

Hindawi

Submit your manuscripts at

www.hindawi.com
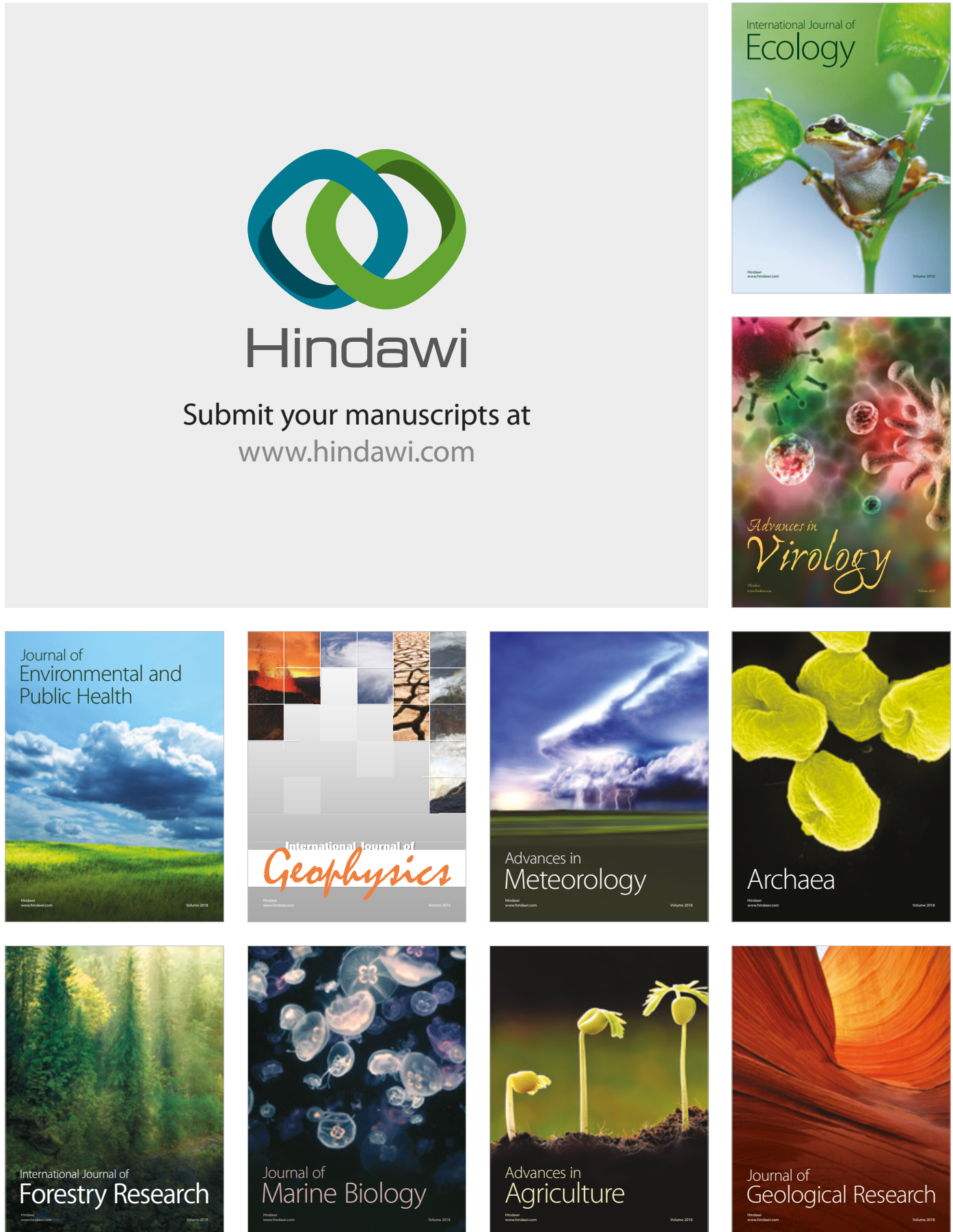

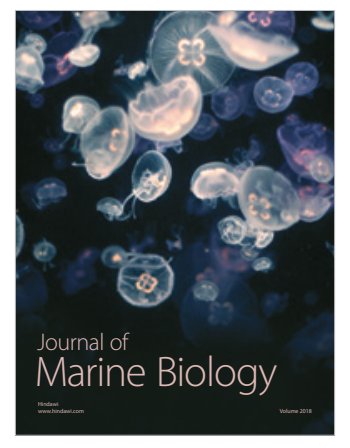

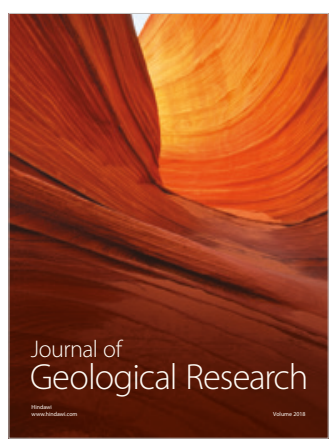

